\title{
O USO DA ANÁLISE HORIZONTAL E VERTICAL PARA APOIAR A EVIDENCIAÇÃO DO ALINHAMENTO ENTRE O BALANÇO SOCIAL E O RELATÓRIO DE SUSTENTABILIDADE: UM ESTUDO EM UMA EMPRESA GERADORA DE ENERGIA ELÉTRICA
}

\author{
THE USE OF HORIZONTAL AND VERTICAL ANALYSIS TO SUPPORT THE \\ DISCLOSURE OF ALIGNMENT BETWEEN THE SOCIAL BALANCE AND \\ SUSTAINABILITY REPORT: A STUDY IN AN ELECTRICITY GENERATING COMPANY
}

Deisy Cristina Corrêa Igarashi

Doutora pela UFSC em Engenharia de Produção (2009), Docente da UNIOESTE

campus Foz do Iguaçu, vinculada ao CCSA

Cristiane Ribeiro de Oliveira

Graduada pela UNIOESTE em Ciências Contábeis (2009)

Reginaldo Adriano da Silva

Graduado pela UNIOESTE em Ciências Contábeis (2008)

\section{Wagner Igarashi}

Doutor pela UFSC em Engenharia e Gestão do Conhecimento (2009), Docente da UNIOESTE campus Foz do Iguaçu, vinculado CESE
Recebido em: 26/08/2009 Aprovado em: 27/07/2010

\section{RESUMO}

O objetivo deste estudo foi observar se as técnicas de análise vertical e horizontal apoiam a evidenciação das informações divulgadas no balanço social, e também se estas estão quantificadas e alinhadas às informações qualitativas apresentadas no relatório de sustentabilidade. Este trabalho exploratório fez uso de abordagem quantitativa e qualitativa, e se limitou a analisar os relatórios de uma única empresa. Tal análise foi realizada a partir de pesquisa documental, fundamentada na leitura do conteúdo dos relatórios publicados pela referida empresa. Para tabular as informações, foram utilizadas planilhas eletrônicas. Como resultado, observou-se que não foi evidenciado alinhamento entre os dois relatórios. No balanço social, o foco de aplicação de recursos foi o agrupamento "indicadores sociais internos". No relatório de sustentabilidade em 2004 e 2005, não ficou evidenciado o objetivo da organização em termos de aplicação de recursos. Em 2006, tal prática foi enfatizada, mas o relatório de sustentabilidade enfocou o agrupamento "meio ambiente", sendo que esta afirmação não é observada em termos de montante de investimento no balanço social.

Palavras-chave: balanço social, relatório de sustentabilidade, análise horizontal e vertical. 


\section{ABSTRACT}

The objective study is to observe the techniques of vertical and horizontal analysis support in the disclosure of information evidencing contained in the social balance, and also if these are quantified and aligned to the qualitative information presented in the sustainability report. This exploratory work made use of quantitative and qualitative approach, and it was limited to analyze reports of a single company. This analysis was based on documental research, from reading the contents of the reports published by the company. Electronic spreadsheets are used to tabulate information. The observed result was that no alignment was evidenced among the two reports. In social balance, the resources investment focus was on grouping 'internal social indicators'. In 2004 and 2005 sustainability report, the organization objective is not evidenced in resources application terms. In 2006 such practice is emphasized, but the sustainability report focuses on the grouping 'environment', and this declaration is not observed in investment amount terms in social balance.

Keywords: social balance, sustainability report, horizontal and vertical analysis.

\section{INTRODUÇÃO}

A responsabilidade das empresas diante da sociedade é uma tendência para a sobrevivência das mesmas. Esta prática não deveria ser utilizada apenas como um apelo de marketing, mas com vistas a refletir uma mudança ética no comportamento da empresa e de seus stakeholders. Observa-se que as ações vinculadas à responsabilidade social são divulgadas principalmente no balanço social, o qual apresenta informações quantitativas sobre os projetos das organizações; e, também, pelo relatório de sustentabilidade, o qual divulga informações qualitativas sobre as ações sociais da organização, descrevendo suas práticas e seus projetos.

Tais relatórios surgem da necessidade de as empresas prestarem contas à sociedade quanto à forma como os recursos humanos e naturais são utilizados em seu cotidiano. Apesar de a contabilidade possuir o balanço social como ferramenta para disponibilizar informações sociais, sozinho este relatório não gera a possibilidade de analisar ou mesmo comparar as ações realizadas pelas empresas com os resultados divulgados nos demais relatórios, como o relatório de sustentabilidade, por exemplo. Neste sentido, Kroetz (2001) sugeriu a adoção de técnicas de análise de balanço, as quais apoiam o processo de análise do demonstrativo (balanço social).

Este estudo adotou a sugestão de Kroetz (2001). Nesse sentido, tem-se como objetivo observar se há possibilidade de as técnicas de análise vertical e horizontal apoiarem a evidenciação das informações divulgadas no balanço social, e também, em paralelo, constatar se as informações quantificadas no balanço social estão alinhadas às informações qualitativas apresentadas nos relatórios de sustentabilidade.

Como a presente pesquisa configura-se como um estudo exploratório, este se limitou a analisar os relatórios de uma única empresa, a qual atua como geradora de energia elétrica. A partir do objetivo delineado, espera-se responder ao seguinte questionamento: existe alinhamento entre os elementos quantificados no balanço social, quando analisados segundo a ótica da análise horizontal e vertical, e descritos nos relatórios de sustentabilidade da empresa objeto de estudo?

Salienta-se que este estudo optou por analisar em paralelo os relatórios de sustentabilidade e o balanço social, tendo em vista que o primeiro relatório apresenta informações pontuais quanto às ações efetivas da organização, ao passo que o segundo relatório contém apenas informações quantitativas, as quais normalmente são agrupadas de acordo com o modelo do Instituto Brasileiro de Análises Econômicas (Ibase).

Em relação à sua estruturação, este trabalho é composto por mais quatro seções, além desta inicial, de caráter introdutório, a saber: seção de revisão teórica, na qual são apresentados elementos relativos ao balanço social e ao relatório de susten- 
tabilidade, enfocando estudos realizados no contexto nacional. Nesta seção, são relacionados, também, elementos relativos à análise horizontal e vertical. Na seção de resultados observados, são relatadas as análises realizadas quanto ao relatório de sustentabilidade e ao balanço social, ao qual foi aplicada a análise horizontal e vertical. Na seção de considerações finais, são apresentados elementos que respondem ao questionamento proposto pelo estudo, bem como delineiam como o objetivo proposto foi atingido. Por fim, são apresentadas as referências adotadas no desenvolvimento desta pesquisa.

\section{REVISÃO TEÓRICA}

No Brasil, a divulgação de ações sociais empresariais não é obrigatória. Entretanto, o tema vem sendo pesquisado pela comunidade acadêmica desde a década de 1970. Kroetz (2000) relatou que, dentre as ações sociais, destacam-se as da Associação de Dirigentes Cristãos de Empresas (ADCE), a qual, desde 1976, promove encontros anuais e reflexões sobre o tema "Balanço social". Merece destaque, também, o Instituto Brasileiro de Análises Econômicas (Ibase), fundado, em 1977, pelo sociólogo Herbert de Souza. Kraemer (2008) também referiu que, a partir do lançamento, apoiado pelo Pensamento Nacional das Bases Empresariais (PNBE), da Campanha Nacional da Ação da Cidadania contra a Fome, a Miséria e pela Vida, criada em 1997, em parceria com a Gazeta Mercantil, foi lançado o modelo de balanço social do Instituto Brasileiro de Análises Econômicas (Ibase). O autor mencionado observou que, neste período, passou a ocorrer a mobilização empresarial de modo mais significativo dentro do contexto nacional.

A divulgação das informações que evidenciam as práticas de responsabilidade social nas organizações, ainda que não obrigatórias, tem merecido destaque e mobilizado a sociedade. Assim, surgiram instituições que visam a conscientizar as empresas da importância de tais ações. Paiva (2001: 31) mencionou, dentre elas, o Instituto Ethos de Empresa e Responsabilidade Social, o qual considera que "a maior contribuição que as empresas podem dar ao País são educação, saúde, cultura, ecologia". O autor em tela observou que, atualmente, o lbase e o Instituto Ethos são os dois organismos mais atuantes no âmbito nacional nesta área. Estas instituições têm o objetivo de mobilizar e conscientizar as empresas e a sociedade sobre a importância da inserção de políticas administrativas éticas e responsáveis em suas ações.

Para auxiliar e incentivar a divulgação do balanço social, o Instituto Ethos publica um "Guia de elaboração" desde 2001. A referida instituição possui, também, o Prêmio Balanço Social, ao passo que o Ibase confere o Selo do Balanço Social. Custódio \& Moya (2007) consideraram que estas instituições buscam fortalecer suas relações com os diversos públicos por meio de um documento mais consistente e, por consequência, mais confiável. Assim, com a divulgação de pesquisas sobre os impactos ambientais causados pelas atividades empresariais, como aquecimento global, escassez dos recursos naturais e valorização do capital intelectual, bem como a partir da promulgação de leis de defesa aos direitos humanos, as entidades tendem a incluir ações que proporcionem o desenvolvimento sustentável em suas políticas administrativas.

Araújo (2001: 74) afirmou que "as empresas se configuram como um dos elementos mais importantes no desenvolvimento econômico e social de um País. Constituem o meio mais eficiente para atender um grande número de necessidades humanas". Isto indica que, em decorrência da conscientização quanto à "[...] necessidade de preservar e manter o ambiente natural, as empresas passaram a interagir proativamente com o meio ambiente. Por meio de ações socialmente responsáveis, foi possível verificar a mudança por parte [delas] nas questões ambientais" (Bezerra \& Telo, 2007: 39).

Com isso, o termo meio ambiente, sob a ótica empresarial, no contexto nacional, refere-se à relação entre a empresa, a natureza e a sociedade. Queiroz \& Queiroz (2000) observaram a importância das Conferências das Nações Unidas e de tratados internacionais, destacando o encontro realizado no Brasil, em 1992, e a Agenda 21. Neste evento, houve estímulo à determinação de metas e prazos para que os países implantem medidas que reduzam de modo significativo os efeitos negativos sobre o meio ambiente. Neste sentido, Tinoco \& Kraemer (2006: 109) destacaram que "diversas organizações empresariais estão cada vez mais preocupadas com atingir e demonstrar um desem- 
penho mais satisfatório em relação ao meio ambiente".

Nesse processo, as empresas deveriam contribuir para um desenvolvimento social planejado, com vistas a apoiar a existência e a interação de ambientes harmoniosos ao longo do tempo, gerando, assim, o conceito de sustentabilidade (DeEgan \& Blomquist, 2006; Deegan, Rankin \& Tobin, 2002). Para Queiroz \& Queiroz (2000: 78), o conceito sustentabilidade implica "[...] uma visão de negócios que busca refletir em seus resultados, seja [sic] bens ou serviços, os custos ambientais envolvidos com a preservação da natureza e a reparação de danos ambientais já causados, e o retorno social de sua lucratividade financeira". Tinoco \& Kramer (2006) consideraram que a sustentabilidade pode ser segmentada em dimensões, conforme evidencia Quadro 1, a seguir, sendo que as organizações podem atuar em todas as dimensões simultaneamente ou selecionar uma em específico.

Diante das várias dimensões de sustentabilidade, percebe-se que a busca de alternativas para o correto gerenciamento dos recursos naturais, aliados aos avanços tecnológicos, representa novos paradigmas para que a sociedade possa evoluir de forma adequada. Por isso, os diversos ramos da ciência têm desenvolvido pesquisas, que fornecem alternativas para melhoria das condições de vida no meio ambiente. Sob essa ótica, Kuasirikun \& Sherer (2004) observaram que é papel da ciência contábil manter a sociedade informada, por meio do balanço social, sobre as contribuições das entidades para o desenvolvimento sustentável.
Tal afirmação é pautada nas percepções de Ramanathan (1976), Deegan (2002) e Gray et al. (2001), os quais observaram que a Contabilidade tem por função captar e transformar os dados coletados das atividades empresariais em informações relevantes para os usuários. Neste sentido, o balanço social é uma das ferramentas da contabilidade gerencial, que evidencia aos usuários das informações as políticas administrativas das empresas, bem como o grau de comprometimento com questões éticas, direitos humanos e proteção ambiental. Paiva (2001: 33) considerou que o "balanço social é a demonstração contábil que melhor pode evidenciar os investimentos da empresa em ações sociais, ambientais e humanas, mostrando o lado (não mercantil) da atividade empresarial".

Para Kroetz (2001: 53), o objetivo do balanço social é "apresentar a relação existente entre a entidade, os funcionários e a sociedade [...] que apresenta a demonstração dos recursos e das influências (favoráveis e desfavoráveis) recebidas e transmitidas pelas entidades na promoção humana, social e ecológica". Batista (2000: 46) complementou a percepção do autor supracitado ao considerar que "o balanço social [...] para os tomadores de decisões, oferece os elementos essenciais sobre os projetos sociais que a empresa possui ou que pretende realizar; para empregados oferece uma garantia de que as suas expectativas serão reconhecidas pelos seus gestores de forma sistematizada e quantificada".

De acordo com Freire, Nunes \& Botelho (2001), as entidades se utilizam dos balanços sociais para explicitar aos agentes econômicos suas ações em

Quadro 1: As dimensões da sustentabilidade

\begin{tabular}{|l|l|}
\hline Social & $\begin{array}{l}\text { "[...] processo de desenvolvimento sustentado por uma civilização com maior equidade na distribuição de renda e de } \\
\text { bens, de modo a reduzir o abismo entre os padrões de vida dos ricos e dos pobres". }\end{array}$ \\
\hline Econômica & $\begin{array}{l}\text { "[..] alcançada através do gerenciamento e da alocação mais eficiente dos recursos e de um fluxo constante de } \\
\text { investimentos públicos e privados". }\end{array}$ \\
\hline Ecológica & $\begin{array}{l}\text { "[...] aumento da capacidade de utilização dos recursos, limitação do consumo de combustíveis fósseis e de outros } \\
\text { recursos e produtos facilmente esgotáveis, redução da geração de resíduos e de poluição, através da conservação de } \\
\text { energia, de recursos e da reciclagem". }\end{array}$ \\
\hline Espacial & $\begin{array}{l}\text { "[...] dirigida para a obtenção de uma configuração rural-urbana mais equilibrada e melhor distribuição territorial } \\
\text { dos assentamentos humanos e das atividades econômicas". }\end{array}$ \\
\hline Cultural & $\begin{array}{l}\text { "[...] procura por raízes endógenas de processos de modernização e de sistemas agrícolas integrados, que facilitem } \\
\text { a geração de soluções específicas para o local, o ecossistema, a cultura e a área". }\end{array}$ \\
\hline
\end{tabular}

Fonte: Tinoco \& Kramer (2006: 137). 
programas sociais para empregados (salários, benefícios etc.), entidades de classe (associações, sindicatos etc.), governo (impostos) e cidadania (parques, praças, meio ambientes, entre outros). Kroetz (2001: 71) considerou que o "balanço social deve demonstrar, [...] as políticas praticadas e seus reflexos no patrimônio, objetivando evidenciar sua participação no processo de evolução social". Freire, Nunes \& Botelho (2001: 71) relataram que "[...] o balanço social é um documento que reúne um conjunto de informações sobre as atividades da empresa orientada para uma melhor gerência dos recursos humanos e naturais, e das relações com o público externo".

Deste modo, a empresa pode apresentar uma união de interesses, devendo prestar informações a seus diversos parceiros, não enfocando apenas informações financeiras (Tinoco \& KRAEMER, 2006). Neste sentido, o balanço social contempla elementos que podem interessar a toda a sociedade.

As legislações de países desenvolvidos preveem a obrigatoriedade do balanço social. Batista (2000: 42) mencionou que "o balanço social francês, obrigatório desde 1977, é dividido em sete capítulos: emprego; remunerações e encargos sociais; condições de higiene e segurança; outras condições de trabalho; formação profissional; relações profissionais; outras condições de vida dependentes da empresa". O balanço social francês está voltado aos órgãos de regulação dos empregados e, após sua aprovação, é enviado ao respectivo inspetor do trabalho (Freire, Nunes \& Botelho; 2001). O balanço social belga está fundamentado nos postulados da continuidade da atividade empresarial. Este demonstrativo contém o número de empregados do exercício corrente e do exercício anterior; o movimento de entrada e saída dos efetivos do quadro durante o exercício corrente e no exercício anterior; e as medidas adotadas em favor dos empregados, reduzindo assim o número de indicadores sociais (BATISTA, 2000). O modelo norte-americano tem como objetivo cuidar da imagem da empresa, e traduz em termos monetários as vantagens e desvantagens e os prejuízos sociais. Por fim, o modelo alemão tenta sintetizar o modelo norte-americano e o francês (KROETZ, 2001).

A estrutura do balanço social, segundo o modelo do Instituto Brasileiro de Análises Econômicas
(Ibase), deve conter informações sobre os seguintes aspectos: (a) recursos humanos; (b) atuação da empresa na comunidade e do bem-estar social; (c) atuação na proteção do meio ambiente (TINOco \& Kraemer, 2006). As empresas brasileiras que optam por publicar o balanço social seguem o modelo proposto pelo Ibase, em sua grande maioria, apesar de existirem os indicadores do Instituto Ethos de Responsabilidade Social (Custódıo \& MoyA, 2007).

Segundo Cavalcante (2006), as empresas têm divulgado seu envolvimento em questões ambientais por meio do balanço social anexo às demonstrações contábeis. Assim, os dados fornecidos pelo balanço social são transmitidos como uma forma de prestação de contas à sociedade, revelando suas influências nos ambientes internos e externos. Underman (2000), Freire, Nunes \& Botelho (2001) e Newson \& Deegan (2002) mencionaram que os balanços sociais existentes são demonstrativos técnicos gerenciais que englobam conjuntos de informações sobre a empresa e permitem analisar sua performance social.

Diante desta percepção, o presente estudo faz uso dos índices de análise horizontal e vertical, a fim de identificar o perfil dos investimentos realizados no balanço social ao longo do tempo e os elementos priorizados pela entidade a cada período. A adoção da técnica de análise vertical e horizontal junto ao balanço social se justifica a partir da percepção de Marion (2009), o qual julgou que as demonstrações financeiras não oferecem informações detalhadas sobre suas variações. Em função disto, o referido autor considerou ser necessária a aplicação de técnicas de análise das demonstrações. Ainda sobre o tema, Matarazzo (2007) destacou que, dentre outras informações, essa técnica revela a situação econômico-financeira, o desempenho, a eficiência na utilização dos recursos, o quadro evolutivo, as tendências e as perspectivas. Especificamente sobre o uso das técnicas de análise das demonstrações financeiras, aplicadas ao balanço social, Kroetz (2001: 62) afirmou que a análise do balanço social é "realizada no âmbito da própria demonstração, sem correlação com o conjunto de demonstrações contábeis da entidade".

Dentre as técnicas de análise, este estudo fez uso especificamente da análise vertical e da horizontal. Marion (2009) observou que, na análise 
vertical, determina-se a porcentagem de cada conta ou grupo de contas em relação ao conjunto (coeficientes). E, no caso da análise horizontal, estabelece-se a relação entre os componentes de um mesmo conjunto (quocientes), comparando-os entre sucessivos períodos (índices). Assaf Neto (2010) destacou que a finalidade da análise horizontal é caracterizar tendências, enquanto que a análise vertical avalia a estrutura da composição dos itens e sua evolução. A prática de análise vertical e horizontal parte de classificações preestabelecidas e evidencia a evolução e a representatividade dos valores expressos no exercício em comparação com os exercícios anteriores.

\section{METODOLOGIA DA PESQUISA}

Este estudo apresenta a análise realizada nos relatórios (balanço social e relatório de sustentabilidade) da Itaipu Binacional, relativos aos exercícios de 2004 a 2006. Os demonstrativos para a análise foram obtidos inicialmente a partir da publicação anual impressa, realizada pela própria empresa, denominada "Relatório de sustentabilidade", um documento que apresenta tanto informações do relatório de sustentabilidade como também divulga o balanço social. Destaca-se que, a partir de 2006, esta publicação passou a ser feita via Internet pelo site da empresa (ITAIPU, 2006).

Ao realizar a análise dos relatórios descritos, o presente trabalho pode ser considerado como uma pesquisa documental. Neste tipo de pesquisa, "são investigados documentos com o propósito de descrever e comparar usos e costumes, tendências, diferenças e outras características" (BERVIAN \& SIIVA, 2007: 62). Lima (2004) ressaltou a importância desta técnica de pesquisa, pois se trata de uma fonte de dados e informações indispensável quando se deseja explorar os temas em estudo. Embora a pesquisa documental possua características semelhantes à pesquisa bibliográfica, na visão de Silva (2003: 61), esta modalidade de pesquisa investiga "documentos [...], como registros, anais, regulamentos, circulares, ofícios, memorandos, balancetes, comunicações informais".

Salienta-se que, nos documentos selecionados, foi realizada a análise de conteúdo. Segundo Bardin (2002: 38), neste tipo de análise, é aplicado "[...] um conjunto de técnicas de análise das comunica- ções que utiliza procedimentos sistemáticos e objetivos de descrição do conteúdo das mensagens". Minayo (2003: 74) enfatizou que a análise de conteúdo visa a verificar hipóteses e/ou a descobrir o que está por trás de cada conteúdo manifesto. Vergara (2005) considerou que este tipo de análise é uma técnica aplicada ao tratamento de dados que visa a identificar o que está sendo dito a respeito de determinado tema. Bardin (2002) complementou que a técnica tem o propósito de obter, a partir de procedimentos sistemáticos e objetivos, a descrição do conteúdo das mensagens (quantitativos ou não) que permitam a inferência de conhecimentos relativos às condições de produção/recepção das mensagens. Como na análise de conteúdo existe a possibilidade de se analisarem elementos quantitativos ou não, optou-se, neste estudo, por se aplicar a análise segundo a ótica qualitativa e quantitativa.

Bauer \& Gaskell (2002) afirmaram que a pesquisa qualitativa é aquela que não utiliza números, mas interpreta a realidade social. Vieira \& Zouain (2006: 18) complementaram, ressaltando que "a pesquisa qualitativa geralmente oferece descrições ricas e bem fundamentadas, além de explicações sobre processos em contextos locais identificáveis". Nesse sentido, foi aplicada a pesquisa qualitativa ao analisar-se o relatório de sustentabilidade da empresa objeto de estudo. Nesta análise, busca-se identificar se o relatório de sustentabilidade está alinhado com as informações apresentadas no balanço social. Para tabular as informações apresentadas no relatório de sustentabilidade, foram utilizadas planilhas eletrônicas. A análise buscou agrupar e ordenar as informações apresentadas no relatório de sustentabilidade, ano a ano, de acordo com os agrupamentos delineados no balanço social da empresa.

Com relação à análise quantitativa, Bauer \& Gaskell (2002) consideraram que este tipo de pesquisa explica os dados através de números e pode fazer uso de "instrumentos estatísticos, tanto na coleta quanto no tratamento dos dados. Esse procedimento não é tão profundo na busca do conhecimento da realidade dos fenômenos, uma vez que se preocupa com o comportamento geral dos acontecimentos" (Raupp \& Beuren, 2006: 92). A partir do exposto, este estudo também é considerado quantitativo, pois, ao se aplicarem as técnicas de análise vertical e horizontal no balanço social, buscou-se observar 
a proporção de investimento em cada agrupamento, bem como conferir como estes têm se comportado ao longo do tempo.

Em relação à comparação das duas abordagens, Goldenberg (1999: 50) observou que, "enquanto os métodos quantitativos supõem uma população de objetos comparáveis, os métodos qualitativos enfatizam as particularidades de um fenômeno". Neste sentido, ao se aplicarem as técnicas de análise vertical e horizontal, considera-se ser possível comparar a proporção dos investimentos, bem como a sua evolução ao longo do tempo, caracterizando assim o estudo como quantitativo. Além disso, ao proceder-se à análise dos relatórios de sustentabilidade, reordenado segundo os agrupamentos do balanço social, tornou-se possível observar a peculiaridade de cada um dos elementos descritos no relatório e comparar a descrição observada com as proporções de valores investidos em cada agrupamento, bem como ao longo do tempo.

\section{RESULTADOS OBSERVADOS}

A partir de 2002, as empresas do setor elétrico, reguladas pela Agência Nacional de Energia Elétrica, por meio da Resolução n. 444/2001, foram orientadas a elaborar um "Relatório de responsabilidade social" , juntamente com a divulgação do balanço social. A primeira demonstração elaborada pela entidade objeto de estudo foi denominada balanço social e refere-se ao exercício de 2003.

Porém, as informações contidas nessa demonstração são, em sua grande maioria, referentes ao novo compromisso da entidade, conforme evidenciado no relatório de 2004 "[...] o ano de 2003 foi de questionamentos, 2004 pode ser considerado ano de ajustes" (ITAIPU, 2004: 1). Deste modo, as estruturas de 2003 diferem das dispostas nos relatórios dos exercícios subsequentes; portanto, não são permitidas comparações. Na sequência, são apresentados os resultados das análises referentes aos exercícios de 2004 a 2006.

\subsection{Análise do balanço social segundo a ótica da análise vertical e horizontal}

Salienta-se que somente a apresentação dos valores divulgados pelas demonstrações contábeis, em muitos casos, não proporcionam informações úteis a todos os usuários. Contudo, por meio da técnica de análise de balanço, podem-se extrair desses relatórios informações numéricas, a fim de auxiliar os usuários destes demonstrativos a conhecerem a situação da entidade, bem como apoiálos no processo de tomada de decisão.

O balanço social tem como enfoque a importância da organização para a vida em sociedade e evidencia as práticas empresariais responsáveis. Esta peça contábil contém valores sobre investimentos em favor dos seguintes elementos: (a) público interno (indicadores sociais internos), o qual aborda alimentação, saúde, capacitação e desenvolvimento profissional, dentre outros benefícios; (b) comunidade (indicadores sociais externos), que se refere aos valores gastos, como educação, cultura, saneamento e esportes, dentre outros, além de informações no desenvolvimento de programas em favor do meio ambiente; (c) investimentos ao meio ambiente, que estão vinculados aos indicadores de investimentos relacionados com a produção/operação da empresa e investimentos em programas e/ou projetos externos.

Este estudo-piloto aplicou a técnica de análise horizontal no balanço social da empresa objeto de estudo, tomando por base os valores do exercício de 2004. A partir de tal prática, buscou-se acompanhar a evolução dos valores investidos pela entidade em benefício de indicadores sociais internos, externos e de meio ambiente, ao longo dos exercícios de 2005 e 2006. Outra técnica aplicada nesse estudo foi a análise vertical, a qual parte do valor destinado em cada item em particular, em relação ao montante total de investimento em cada exercício. Esta técnica revela qual agrupamento apresentou maior relevância nos exercícios analisados.

Em relação aos recursos investidos no período analisado e apresentado na Tabela 1, observou-se que a entidade objeto de estudo apresentou um aumento de 52\% no total de investimentos de 2004 para 2006. Este montante foi segmentado entre os três perfis de indicadores (sociais internos, sociais externos, de meio ambiente).

Ao longo dos anos analisados, verificou-se que, no exercício de 2004 , foi investido um total de $67 \%$ do montante em indicadores sociais internos, os 
Tabela 1: Balanço social da empresa objeto de estudo, após inserção da análise vertical (AV) e da análise horizontal (AH) para o período de 2004 a 2006

\begin{tabular}{|c|c|c|c|c|c|c|}
\hline \multirow[t]{2}{*}{ Indicadores do balanço social } & \multicolumn{2}{|c|}{2004} & \multicolumn{2}{|c|}{2005} & \multicolumn{2}{|c|}{2006} \\
\hline & AV & $\mathrm{AH}$ & AV & $\mathrm{AH}$ & AV & $\mathrm{AH}$ \\
\hline Alimentação & $4 \%$ & $100 \%$ & $4 \%$ & $122 \%$ & $5 \%$ & $157 \%$ \\
\hline Encargos sociais compulsórios & $18 \%$ & $100 \%$ & $17 \%$ & $122 \%$ & $14 \%$ & $122 \%$ \\
\hline Previdência privada & $16 \%$ & $100 \%$ & $15 \%$ & $117 \%$ & $14 \%$ & $135 \%$ \\
\hline Saúde & $12 \%$ & $100 \%$ & $16 \%$ & $175 \%$ & $19 \%$ & $236 \%$ \\
\hline Segurança e medicina do trabalho & $1 \%$ & $100 \%$ & $0 \%$ & $58 \%$ & $0 \%$ & $98 \%$ \\
\hline Educação & $3 \%$ & $100 \%$ & $3 \%$ & $99 \%$ & $2 \%$ & $111 \%$ \\
\hline Capacitação e desenvolvimento profissional & $1 \%$ & $100 \%$ & $1 \%$ & $201 \%$ & $1 \%$ & $127 \%$ \\
\hline Creches ou auxílio-creche & $0 \%$ & $100 \%$ & $0 \%$ & $177 \%$ & $0 \%$ & $298 \%$ \\
\hline Participação nos lucros ou resultados & $5 \%$ & $100 \%$ & $6 \%$ & $152 \%$ & $8 \%$ & $255 \%$ \\
\hline Outros & $7 \%$ & $100 \%$ & $3 \%$ & $62 \%$ & $8 \%$ & $191 \%$ \\
\hline Total de indicadores sociais internos & $67 \%$ & $100 \%$ & $65 \%$ & $126 \%$ & $74 \%$ & $168 \%$ \\
\hline Educação & $7 \%$ & $100 \%$ & $8 \%$ & $148 \%$ & $6 \%$ & $148 \%$ \\
\hline Cultura & $4 \%$ & $100 \%$ & $2 \%$ & $64 \%$ & $1 \%$ & $68 \%$ \\
\hline Saúde e saneamento & $4 \%$ & $100 \%$ & $4 \%$ & $140 \%$ & $5 \%$ & $204 \%$ \\
\hline Esporte & $0 \%$ & $100 \%$ & $0 \%$ & $216 \%$ & $1 \%$ & $3705 \%$ \\
\hline Outros & $5 \%$ & $100 \%$ & $7 \%$ & $210 \%$ & $4 \%$ & $151 \%$ \\
\hline Total de indicadores sociais externos & $18 \%$ & $100 \%$ & $21 \%$ & $145 \%$ & $17 \%$ & $143 \%$ \\
\hline $\begin{array}{l}\text { Investimentos relacionados com a produção/operação } \\
\text { da empresa }\end{array}$ & $4 \%$ & $100 \%$ & $2 \%$ & $79 \%$ & $1 \%$ & $71 \%$ \\
\hline Investimentos em programas e/ou projetos externos & $11 \%$ & $100 \%$ & $12 \%$ & $139 \%$ & $8 \%$ & $116 \%$ \\
\hline Total de indicadores sociais de meio ambiente & $15 \%$ & $100 \%$ & $14 \%$ & $124 \%$ & $9 \%$ & $93 \%$ \\
\hline Total geral & $100 \%$ & $100 \%$ & $100 \%$ & $129 \%$ & $100 \%$ & $152 \%$ \\
\hline
\end{tabular}

Fonte: Dados da pesquisa.

quais, deste exercício para o de 2006, aumentaram em $68 \%$. Os indicadores internos apresentados pela organização objeto de estudo foram os seguintes: "alimentação", "encargos sociais compulsórios", "previdência privada", "saúde", "segurança e medicina do trabalho", "educação", "capacitação e desenvolvimento profissional", "creches ou auxílio-creche", "participação nos lucros ou resultados" e "outros". Destes indicadores, os que apresentaram um investimento mais expressivo foram "encargos sociais compulsórios", "previdência privada" e "saúde", com, respectivamente, $18 \%, 16 \%$ e $12 \%$, os quais, do exercício 2004 para 2006, apresentaram um aumento respectivo de $22 \%$, 35\% e $136 \%$.
Os indicadores sociais externos foram compostos pelos elementos a seguir: "educação", "cultura", "saúde e saneamento", "esporte" e "outros". Destaca-se que o montante total investido neste grupo representa $18 \%$ do total do balanço social em 2004, e individualmente nenhum dos indicadores foi considerado expressivo, por representarem menos de $10 \%$ do total investido. O maior investimento foi realizado no item "educação", no valor de $\$ 7.697 .000,00$, o que representa $7 \%$ dos $18 \%$ do grupo. Ao se compararem os investimentos em "educação" de um período para outro, observou-se um aumento de $45 \%$, mas este aumento não foi relevante a ponto de o indicador passar a ser considerado expressivo. 
Finalmente, em relação aos indicadores de meio ambiente, estes foram compostos por dois índices: "investimentos relacionados com a produção/ operação da empresa" e "investimentos em programas e/ou projetos externos", sendo, neste caso, expressivo apenas o investimento de $11 \%$ realizado no segundo indicador, para o ano de 2004. Observou-se que, quando se analisou este grupo de indicadores de um período para outro, o indicador "investimentos relacionados com a produção/ operação da empresa" está deixando de ser objeto de investimento, uma vez que, nos períodos analisados, ele reduziu de $4 \%$ para $2 \%$, e para $1 \%$ no último período. No que se refere ao indicador "investimentos em programas e/ou projetos externos", apesar de ele ter se reduzido de $11 \%$ para $8 \%$, não foi possível afirmar que este também esteja deixando, ou não, de ser objeto de investimento pela organização.

\subsection{Análise dos relatórios de sustentabilidade}

Os relatórios de sustentabilidade apresentam um conjunto de informações qualitativas sobre o desempenho e o relacionamento da entidade com seu público interno, sociedade (externo) e meio ambiente. A partir do exercício de 2004, o balanço social da empresa objeto de estudo tem sido apresentado em anexo ao seu relatório de sustentabilidade.

Analisando-se os relatórios de sustentabilidade da organização objeto de estudo, notou-se a evolução destes em relação ao aspecto social. O texto introdutório referente ao exercício de 2004 destaca que, ao longo dos 31 anos de existência, a entidade desenvolveu projetos voltados para a questão socioambiental. Conforme relato coletado:

[...] não seria difícil atender às novas determinações. Porém, dentro da própria empresa, havia questionamentos e até sinais de rejeição a essa filosofia: afinal, por que se falar em responsabilidade socioambiental, [...] sendo que a entidade e os próprios empregados, em ações isoladas, já cumpriam ou achavam que cumpriam suas obrigações com a comunidade (ITAIPU, 2004: 5).

O texto acima indica que, mesmo com o desenvolvimento de projetos isolados, a responsabilidade socioambiental não era o objetivo central da entidade. Observou-se que, segundo descrito no relatório de sustentabilidade de 2005, este apresentou resultados positivos ao reconhecer que "[...] a responsabilidade social e o cuidado com o meio ambiente são atividades permanentes da empresa, da mesma forma que o é a geração de energia" (ITAIPU, 2005: 12). Outro elemento relativo à reafirmação da importância de tal relatório foi observado no exercício de 2006, junto ao seguinte relato "Ao publicar este relatório de sustentabilidade, [...] reafirma seu compromisso com a ética e a transparência em seu negócio" (ITAIPU, 2006: 3). Destacase que, por meio da análise dos relatórios, foi possível constatar que os objetivos estratégicos e as políticas e diretrizes permaneceram os mesmos ao longo dos exercícios, assim como as informações sobre a estrutura da entidade.

Quanto à estrutura dos relatórios, o exercício de 2004 foi subdividido nos seguintes itens: "informações da empresa", "diálogo com públicos estratégicos", "comunidade" e "meio ambiente". Ao passo que o relatório referente ao exercício de 2005 foi organizado por projetos, enquanto que o referente ao exercício de 2006 foi estruturado em "gestão", "meio ambiente", "social", "público interno", "indicadores", "relatório dos auditores".

As informações da empresa em 2004 evidenciaram a preocupação com o relacionamento entre a entidade e seus funcionários. Contudo, estas informações possuem características informativas e apresentam os valores investidos somente em determinados programas. Quando se realizou a comparação destas informações, com o exercício de 2005, notou-se que há uma alteração quanto à disposição das mesmas. Em 2005, por exemplo, mencionaram-se os valores investidos em projetos, os quais, em sua maioria, foram desenvolvidos em prol do público interno. No exercício de 2006, não foram listados os valores investidos nos projetos, e o relatório apresentou uma nova estrutura distinta da proposta em 2004, e, também, da proposta em 2005. Apesar das alterações estruturais nos relatórios de um período para outro, foi possível observar que os programas mencionados em 2004 permaneceram os mesmos em 2005 e em 2006, havendo variações somente quanto à disposição das informações. 
Em relação às informações apresentadas pela entidade quanto ao "diálogo com públicos estratégicos", observou-se que, nos três exercícios, as ações evidenciaram elementos vinculados ao público interno, ou seja, seus funcionários. Quanto às informações direcionadas à "comunidade", o relatório de 2004 mencionou a disponibilização de "[...] 15 milhões para investimento em programas de responsabilidade social - o montante atende ao Brasil e ao Paraguai, igualitariamente. [...] todos os programas socioambientais provêm de juros de aplicações financeiras, vendas de sucatas, aluguéis de imóveis, entre outros" (ITAIPU, 2004: 17).

Verificou-se que os projetos mencionados no item "comunidade", no exercício de 2004, permanecem os mesmos em 2005. Ao se compararem as informações de 2004 e 2005, observou-se que, no exercício de 2005, foram evidenciados os valores aplicados em todos os projetos, ao contrário do exercício de 2004. No exercício de 2006, o relatório deixou de apresentar os valores referentes aos incentivos no turismo. Destaca-se que as informações constantes nos relatórios de 2005 e 2006 não mencionaram a origem dos recursos aplicados nos projetos.

Com relação ao "meio ambiente", as informações disponibilizadas e os projetos desenvolvidos pela entidade nos relatórios de sustentabilidade de 2004 a 2006 permaneceram as mesmas, com exceção do projeto "Educação ambiental", o qual foi iniciado em 2005 e não explicitou valores. Na análise dos relatórios de sustentabilidade, observouse a disposição e o caráter das informações inerentes a cada exercício e à continuidade dos programas, para que possam ser comparadas as informações evidenciadas com os índices obtidos por meio da aplicação da análise horizontal e vertical ao balanço social.

\subsection{Potencialidades e pontos a serem melhorados com relação às informações apresentadas}

Diante da análise dos relatórios de sustentabilidade e aplicação da técnica de análise horizontal e vertical no balanço social de 2004 a 2006, da entidade objeto de estudo, observou-se que ambos os relatórios preservaram informações sobre a questão da autenticidade. O relatório referente ao exercício de 2004 tem como página inicial a carta dos Auditores Independentes, que fizeram a certificação dos demonstrativos, sendo que este documento foi finalizado no segundo semestre de 2005. O relatório de 2005, por sua vez, foi analisado no primeiro semestre do ano subsequente, ou seja, em 2006. Esse relatório revelou, ainda, a evolução na avaliação feita e relata um salto de 51 pontos, adquiridos em 2004, para 143 em 2005. Salientase que o total de pontos desta escala atinge, no máximo, 200. Entretanto, o relatório de 2005 menciona que, por problemas orçamentários, este não passou por um processo de auditoria independente. Constatou-se, ainda, que as informações publicadas no relatório de 2006 apresentaram uma evolução em relação ao relatório de 2005, passando para 163 pontos, segundo a avaliação relatada.

As informações sobre o novo compromisso da empresa com o meio ambiente foram evidenciadas nos dois relatórios. Tal prática permite ao leitor acompanhar as medidas tomadas, a fim de que fossem atingidos os objetivos da organização em relação à sociedade.

Em 2005, o relatório apresentou o amadurecimento de novos objetivos, por meio da troca de Notas Reversais entre os governos do Brasil e do Paraguai, os quais reconheceram que, assim como a geração de energia, a responsabilidade socioambiental passou a ser objetivo estratégico da empresa. A criação do comitê gestor em 2005 relatou a iniciativa da entidade em acompanhar, disponibilizar e propor projetos que possam atender, de forma objetiva, ao público interno, ao externo e ao meio ambiente. Quanto às informações dispostas nos relatórios, pode-se considerar que estas permaneceram as mesmas durante os exercícios de 2004 a 2006, sendo diferenciadas apenas pelas formas de apresentação (agrupamentos) em cada período.

Por exemplo, as informações sobre meio ambiente em 2005 são apresentadas por tópicos, como "Cultivando água boa", "Cuidando da biodiversidade" e "Práticas agrícolas sustentáveis", ou seja, de modo distinto a 2004 e a 2006. Tal mudança pode vir a dificultar a compreensão dos usuários do relatório. Ainda sobre as informações relacionadas ao meio ambiente, observou-se que os relatórios de sustentabilidade analisados apresentaram as mesmas informações sobre o projeto "Cultivan- 
do água boa", apenas com a ausência de dados sobre valores investidos na "Educação ambiental", em 2004, e na "Coleta solidária e destinação de resíduos", em 2006.

No relatório de sustentabilidade de 2006, foi mencionado que o foco da empresa é o meio ambiente. Este tema ocupou o primeiro capítulo do relatório, com ênfase para o prêmio "Destaque Nacional em Meio Ambiente, Desenvolvimento Sustentável e Responsabilidade Social", e o programa "Cultivando água boa", o qual foi considerado a melhor ação ambiental desenvolvida por empresas do setor elétrico. Contudo, os dados que foram revelados pela análise horizontal e vertical do balanço social de 2004 a 2006 demonstram que os investimentos no meio ambiente passaram de $15 \%$ do montante total investido em 2004 para 9\% em 2006. A análise evidenciou que, ao longo dos exercícios, houve uma queda de $7 \%$ nos investimentos do grupo meio ambiente.

Destaca-se que os indicadores internos, em todos os exercícios analisados, foram os itens de maior relevância para a entidade, em termos de direcionamento de recursos, conforme o balanço social. Contudo, ao se observarem apenas os relatórios de sustentabilidade, o usuário da informação pode ser conduzido a uma interpretação incorreta, uma vez que este relatório evidencia de modo mais pontual as ações direcionadas ao meio ambiente e à sociedade.

Notou-se ainda que a ausência de dados em determinados projetos/ações no decorrer dos exercícios e as mudanças de enfoque na apresentação das informações dificultam a compreensão e a comparação que os usuários dos relatórios poderiam realizar. Contudo, mesmo dispostos de formas diferentes, e com variação nos valores investidos, os projetos desenvolvidos pela entidade tiveram continuidade, ou seja, eles permaneceram os mesmos ao longo dos exercícios analisados.

\section{CONSIDERAÇÕES FINAIS}

Considera-se, atualmente, que as questões sociais possuem relevância equivalente à abordagem econômica e financeira, quando se observam os fatores determinantes para a sobrevivência das entidades. Isso tem ocorrido porque as entidades têm se configurado como um bem comum, abandonando a percepção de maximização de lucros a qualquer custo. Neste sentido, houve uma evolução, pois as entidades demonstram maiores preocupações com determinados elementos, como escassez de recursos naturais, legislação de proteção ao meio ambiente e leis trabalhistas.

Observou-se que algumas empresas têm considerado em seu planejamento estratégico a destinação de recursos financeiros em ações que promovam o bem-estar de seus funcionários, e proporcionem às comunidades em seu entorno a agregação de valor para a economia local, em busca do desenvolvimento sustentável. Assim, são criados mecanismos que possibilitam a redução das desigualdades sociais, a partir de parcerias com órgãos públicos e privados, aumento na capacidade de utilização dos recursos naturais, bem como a preservação ambiental e maior valorização da cultura local das comunidades situadas ao redor das empresas.

Sob essa ótica, as empresas, ao desenvolverem ações e projetos, têm divulgado, juntamente com os demais relatórios exigidos por lei, um conjunto de informações qualitativas e quantitativas sobre os benefícios gerados em favor de seus funcionários, da sociedade e do meio ambiente. Dentre as demonstrações que divulgam tais ações, estão o balanço social e o relatório de sustentabilidade.

Em linhas gerais, o balanço social deveria atender a todos os usuários das demonstrações. Este demonstrativo deveria proporcionar aos trabaIhadores a possibilidade de verificar os benefícios adicionais e autoconhecimento de seu ambiente de trabalho. Aos acionistas, deveria gerar informações complementares às demonstrações financeiras e servir como base temporal para o planejamento de investimentos futuros. Aos fornecedores e ao governo, tal demonstrativo deveria respectivamente gerar confiança e possibilitar a observação do desempenho das atividades da organização. Para a sociedade, de modo geral, deveria ser possível observar o retorno gerado para ela em contrapartida à utilização de seus recursos.

O cenário descrito configura-se como uma das preocupações da ciência contábil, uma vez que esta busca tornar a informação contábil acessível a todos 
os seus usuários, a fim de que estes possam atingir seus objetivos ao fazer uso dos relatórios. Para isso, as informações precisam apresentar caráter preditivo e estar à disposição em tempo hábil, de forma que os usuários possam tomar suas decisões a partir das informações apresentadas. Salienta-se que, neste processo, é importante gerar relatórios que sejam passíveis de comparações no decorrer do tempo e, também, com outras entidades.

Considerando o enfoque descrito, este estudo buscou observar se as técnicas de análise vertical e horizontal podem apoiar a evidenciação das informações divulgadas no balanço social, e também, em paralelo, verificar se as informações quantificadas no balanço social estão alinhadas às informações qualitativas apresentadas nos relatórios de sustentabilidade.

Com relação ao objetivo vinculado à análise horizontal e vertical realizada junto ao balanço social, primeiramente foi necessário que os dados do balanço social fossem transcritos, para, em um segundo momento, ser aplicada a técnica de análise vertical e horizontal, conforme mostra a Tabela 1. Essa tabela possibilitou visualizar, em termos de proporção (\%), os investimentos priorizados pela empresa no período de 2004 a 2006.

Já com relação ao objetivo vinculado ao relatório de sustentabilidade, o qual tem caráter informativo sobre o compromisso social da organização, fez-se necessário analisar cada um dos relatórios, a fim de identificar as práticas da organização ao longo de cada exercício estudado. Nesta etapa, observou-se inicialmente a falta de padronização das informações, em termos de agrupamento e denominações, fator que dificultou o processo, mas não o inviabilizou, uma vez que foi possível identificar, neste demonstrativo, informações passíveis de comparações futuras com os dos demais relatórios subsequentes. $\mathrm{Na}$ referida etapa, também foram analisados os relatórios referentes aos exercícios de 2004 a 2006.

A partir da análise do balanço social, verificou-se que os elementos priorizados pela entidade ao longo dos exercícios foram os indicadores sociais internos, apesar de o relatório de sustentabilidade não explicitar de modo evidente os grupos de investimentos ou projetos com maior ênfase, mas ter disponibilizado maiores informações acerca de ações vinculadas ao meio ambiente e à sociedade. Neste sentido, pode-se afirmar que, no exercício de 2006, a entidade divulgou, em seu relatório de sustentabilidade, que seu foco de investimento foi o meio ambiente. Esta informação não foi evidenciada pela análise vertical, uma vez que houve uma redução nos investimentos deste grupo, passando de $15 \%$ para $14 \%$ e, finalmente, para $9 \%$. Ao se realizar a análise deste agrupamento, segundo a ótica análise horizontal, observou-se que, de 2004 para 2006, houve uma redução de $9 \%$ nos investimentos relativos ao agrupamento de meio ambiente.

Em relação aos pontos a serem melhorados nos relatórios de sustentabilidade e no balanço social, constatou-se que a empresa possui preocupação com a qualidade das informações divulgadas nesses relatórios. Entretanto, ao se proceder à análise conjunta dos relatórios, verificou-se que: (a) mesmo dispostas de formas diferentes, (b) com variação do valor investido de um período para o outro e (c) com a ausência de algumas informações, as ações em que foram investidos os recursos permaneceram as mesmas ao longo dos exercícios. Este cenário revela certo nível de gerenciamento das ações em termos de responsabilidade social empresarial. Tal prática gera possibilidade de que os usuários das informações realizem possíveis comparações, apesar das inconsistências observadas entre o balanço social e o relatório de sustentabilidade.

Ao se analisar o balanço social, ficaram evidentes as inconsistências mencionadas em relação aos montantes investidos pela empresa no período, os quais foram direcionados aos indicadores sociais internos. Tal afirmação utiliza por base as informações da análise vertical, a qual evidenciou que este grupo representou $67 \%$ e $74 \%$ do total investido em 2004 e 2006, respectivamente; e a análise horizontal demonstrou uma evolução de $68 \%$. Ao passo que, quando se analisa o relatório de sustentabilidade do mesmo período, não ficaram evidenciados os grupos de investimentos ou projetos, aos quais foi atribuída maior ênfase, exceto no exercício de 2006, quando o relatório enfatizou que seu foco de investimento foi o meio ambiente.

No que se refere ao questionamento que direcionou o desenvolvimento deste estudo, quanto a existir alinhamento entre os elementos quantificados no balanço social, quando analisados segundo 
a ótica da análise horizontal e vertical, e descritos nos relatórios de sustentabilidade da empresa objeto de estudo, considera-se que o tal alinhamento não foi evidenciado. Com relação ao balanço social, pode-se confirmar, a partir da análise horizontal e vertical, que o foco de aplicação de recursos da organização de 2004 a 2006 foi o agrupamento de indicadores sociais internos. Ao passo que, no relatório de sustentabilidade, nos períodos de 2004 e 2005, não ficou evidenciado o principal objetivo da organização em termos de aplicação de recursos. Já no exercício de 2006, quando tal prática foi enfatizada, o relatório de sustentabilidade considerou que o foco foi o agrupamento de meio ambiente, sendo que esta afirmação não foi observada em termos do montante de investimento no balanço social, o qual evidenciou maior volume de recursos aplicados aos indicadores sociais internos.

A partir da pesquisa realizada, torna-se possível tecer algumas recomendações para continuidade deste estudo, tais como: (a) analisar outros relatórios, nas bases aqui adotadas, a fim de observar se há alinhamento entre o balanço social e os relatórios de sustentabilidade; (b) fazer comparações com outras entidades do mesmo setor, com o propósito de observar semelhanças e diferenças quanto à representatividade dos investimentos nos diversos grupos de indicadores; e (c) ampliar a base teórica de pesquisa com relação ao contexto internacional, com a intenção de observar a existência de trabalhos realizados nos mesmos moldes aqui apresentado.

\section{REFERÊNCIAS}

Araújo, Francisco José de. Dimensões da responsabilidade social da empresa. Revista Brasileira de Contabilidade, ano 30, n. 129, p. 74, Brasília, Distrito Federal, maio/junho, 2001.

Assaf Neto, Alexandre. Estrutura e análise de balanços: um enfoque econômico-financeiro. 9. ed. São Paulo: Atlas, 2010.

BARDIN, Laurence. Análise de conteúdo. Tradução de Luís Antero Reto e Augusto Pinheiro. Lisboa: Edições 70, 2002.

Batista, Halcima M. Proposta de um modelo de balanço social a ser aplicado nas indústrias têxteis. Pensar Contábil, n. 9, p. 42-46, Rio de Janeiro, agosto/outubro, 2000.

Bauer, Martin W. \& Gaskell, George. Pesquisa qualitativa com texto imagem e som: um manual prático. Tradução de Pedrinho A. Guareschi. Petrópolis: Vozes, 2002.

Bervian, Pedro A.; Cervo, luiz A. \& Silva, Roberto da. Metodologia científica. 6. ed. São Paulo: Pearson Prentice Hall, 2007.

Bezerra, Tainan de L. \& Teló, Admir R. Contabilidade ambiental: o passaporte para a competitividade. Revista do Conselho Regional de Contabilidade do Paraná, n. 148, p. 39-48, Curitiba, 2ํquadrimestre, 2007.
Cavalcante, Carmem H. L. Divulgação e transparência de informações ambientais. Revista Brasileira de Contabilidade, n. 159, p. 63, Brasília, Distrito Federal, maio/junho, 2006.

Custódio, Ana Lúcia de M. \& Moya, Renato. Guia para elaboração de balanço social e relatório de sustentabilidade 2007. São Paulo: Instituto Ethos, 2007.

DeEgan, Craig. The legitimizing effect of social and environmental disclosures: a theoretical foundation. Accounting, Auditing and Accountability Journal, v. 15, n. 3, p. 282-307, Bingley, 2002.

Deegan, Craig \& Blomquist, Christopher. Stakeholder influence on corporate reporting: an exploration of the interaction between WWFAustralia and the Australian minerals industry. Accounting, Organizations and Society, v. 31, n, 4-5, p. 343-372, London, 2006.

Deegan, Craig; Rankin, Michaela \& Tobin, John. An examination of the corporate social disclosures of BHP from 1983-1997: A test of legitimacy theory. Accounting, Auditing and Accountability Journal, v. 15, n. 3, p. 312-343, Bingley, 2002.

Freire, Fátima de S.; Nunes, Florisval M. \& Botelho, Ducineli R. Balanço social abrangente: ferramenta contábil eficaz para mensuração do papel social 


\section{REFERÊNCIAS}

das empresas. Revista Brasileira de Contabilidade, n. 130, p. 23, Brasília, Distrito Federal, julho/ agosto, 2001.

Goldenberg, Mirian. A arte de pesquisar: como fazer pesquisa qualitativa em Ciências Sociais. Rio de Janeiro: Record, 1999.

Gray, Rob; JAVAD, Mohammed; Power, David M. \& SinclaIR, C. Donald. Social and environmental disclosure and corporate characteristics: A research note and extension. Journal of Business Finance and Accounting, v. 28, n. 3-4, p. 327356, West Sussex, April/May, 2001.

ITAIPU BINACIONAL. Coordenadoria de Responsabilidade Socioambiental. Relatório de sustentabilidade. Curitiba: Tuicial Indústria Gráfica Ltda., 2004.

Coordenadoria de Responsabilidade Socioambiental. Relatório de sustentabilidade. Curitiba: Tuicial Indústria Gráfica Ltda., 2005.

Coordenadoria de Responsabilidade Socioambiental. Relatório de sustentabilidade: nós podemos fazer um mundo melhor. Curitiba: Tuicial Indústria Gráfica Ltda., 2006.

Kraemer, Maria Elizabeth P. Responsabilidade social - uma alavanca para a sustententabilidade. Ambiente Brasil, s/d. Disponível em: <http:// www.ambientebrasil.com.br/gestao/sustentabilidade.doc>. Acesso em: 20 de abril de 2008.

Kroetz, César Eduardo S. Balanço social: teoria e prática. São Paulo: Atlas, 2000.

Balanço social: uma proposta de normatização. Revista Brasileira de Contabilidade, ano 30 , n. 129, p. 48-53, Brasília, Distrito Federal, maio/junho, 2001.

KUASIRIKUn, Nongnooch \& Sherer, Michael. Corporate social accounting in Thailand. Accounting, Auditing and Accountability Journal, v. 17, n. 4, p. 629-660, Bingley, 2004.

LIMA, Manolita C. Monografia: a engenharia da produção acadêmica. São Paulo: Saraiva, 2004.

MArion, José Carlos. Análise das demonstrações contábeis: contabilidade empresarial. São Paulo: Atlas, 2009.

Matarazzo, Dante C. Análise financeira de balan- ços: abordagem básica e gerencial. 6. ed. São Paulo: Atlas, 2007.

Minayo, Maria Cecília de S. (Org.). Pesquisa social: teoria, método e criatividade. 22. ed. Petrópolis: Vozes, 2003.

Newson, Marc \& DeEgan, Craig. Global expectations and their association with corporate social disclosures practices in Australia, Singapore and North Korea. The International Journal of Accounting, v. 37, n. 2, p. 183-213, Champaign, 2002.

Palva, Simone B. Cidadania empresarial: aspectos sociais e contábeis. Revista Brasileira de Contabilidade, ano 30, n. 129, p. 30-33, Brasília, Distrito Federal, maio/junho, 2001.

Quelroz, Regiane L. S. \& Quelroz, Eliseu S. A contabilidade como um instrumento de gestão ambiental e empresarial, e sua contribuição à melhoria da qualidade de vida planetária. Pensar Contábil, n. 9, p. 78, Rio de Janeiro, agosto/outubro, 2000. Ramanathan, Kavasseri $V$. Toward a theory of corporate social accounting. The Accounting Review, v. 51, n. 3, p. 516-528, Austin, July, 1976.

Raupp, Fabiano M. \& Beuren, Ilse Maria. Metodologia da pesquisa aplicável às ciências sociais. In: Beuren, Ilse Maria (Org.). Como elaborar trabalhos monográficos em contabilidade: teoria e prática. 3. ed. São Paulo: Atlas, 2006. p. 77-97.

Siıva, Antonio Carlos R. da. Metodologia da pesquisa aplicada à contabilidade - orientações de estudos, projetos, artigos, relatórios, monografias, dissertações, teses. São Paulo: Atlas, 2003.

Tinoco, João Eduardo P. \& Kraemer, Maria Elizabeth P. Contabilidade e gestão ambiental. São Paulo: Atlas 2006.

UnERMAN, Jeffrey. Methodological issues: reflections on quantification in corporate social reporting content analysis. Accounting, Auditing and Accountability Journal, v. 13, n. 5, p. 667-681, Bingley, 2000.

Vergara, Sylvia C. Projetos e relatórios de pesquisa em administração. 4. ed. São Paulo: Atlas, 2005.

VIEIRA, Marcelo M. F. \& Zouain, Deborah M. (Orgs.). Pesquisa qualitativa em administração. 2. ed. Rio de Janeiro: FGV, 2006. 